\title{
The effect of campus unrest on the language proficiency of university students
}

\section{Carryl Allardice}

\begin{abstract}
This report on the extent to which students' English suffers during student unrest is based on responses by a group of black South African students registered for Practical English to a questionnaire administered in the Language Laboratory at a predominantly black university. The rationale behind the questionnaire will be outlined first before proceeding to a detailed analysis of the results.
\end{abstract}

Hierdie verslag oor die mate waarin studente se Engels gedurende studente-onrus agteruit gegaan het, is gegrond op 'n groep Swart Suid-Afrikaanse studente, ingeskryf vir Praktiese Engels, se antwoorde op 'n vraelys. Die vraelys is deur die taallaboratorium van 'n oorwegend Swart universiteit hanteer. Die doel van die vraelys word eers verduidelik. Daarop volg dan 'n uitvoerige ontleding van die uitslae.

Student unrest has become endemic and an annual occurrence since the Soweto riots in 1976. Prior to that year incidents of unrest were more sporadic. In some years unrest has been very brief (a day or two) and in other years it has lasted longer (three or four weeks).

The reasons for these interruptions in the normal academic programme vary from a purely domestic nature, such as dissatisfaction with food, poor heating, to a more general kind sparked off by national events such as the commemoration of significant events like Sharpeville, Biko Day and so on. Two weeks after the commencement of lectures in 1986, a prolonged stay-away began which lasted for two and a half months, the main reason being domestic.

The group of students who were selected for the investigation and who take the Practical English course, must, as part of their course, attend a weekly language laboratory session each of which consists of a module of work which concentrates on one feature of the English language. Pre- and post-language laboratory lectures are also given weekly. In the end-of-year examination at least one compulsory question is based on language laboratory work (Practical English 1986:2). This one-year course carries full academic status for degree purposes and "is primarily a language course aimed at suiting the needs of students taking a variety of degrees in various faculties. It aims at training in effective expression and communication ..." (Proctor \& Verschoor 1978:461). The course includes only two prescribed literary works and does not lead to English II. Although it is regarded as a firstyear course, it accommodates students in any year of their undergraduate studies. It is important to bear this in mind when reading the results of the questionnaire as respondents were not only first-year students. Equally important is the fact that the mother tongue of these students is not English, although all university courses are offered through the medium of English. As Vorster and Proctor have pointed out "All black South Africans have a vernacular language, and they all learn both official languages, English and Afrikaans, at school. It is therefore safe to assume that they have no difficuity whatever in identifying either of the two languages, although they may not necessarily be equally competent in them" (1976:103). 
It was while monitoring these Practical English students' progress in the language laboratory immediately after their absence of two months (due to student unrest) that I became alarmed at the poor quality of their interaction - especially their very poor listening comprehension in English. Likewise their inability to follow simple instructions and express themselves articulately in English were further cause for distress. Discussions with other academic colleagues, who had encountered similar problems with students returning to lectures after periods of unrest, seemed to confirm my own observations. After a week of lectures the Practical English students' performance in the language laboratory had improved noticeably, no doubt as they became familiar with the English spoken by their lecturers and as they attuned their ears to listening to spoken English. Hence it seemed feasible to test this hypothesized deterioration in the English of this group of students during student unrest.

Despite a fairly extensive literature search there appears to have been nothing published about student unrest in South African universities and its effect on student performance. I realise that any ethnographically-based research of this kind and the hypothesis and issues that it raises may prove contentious and controversial. I am also conscious of how limited the data are presented in this paper, but nevertheless feel that an investigation into this area of student activity is necessary.

\section{Questionnaire}

The questionnaire was drawn up in an attempt to establish: firstly, to what extent students are exposed to English while boycotts are in progress, and, secondly, it attempts to find out whether students experience difficulties with English on their return to lectures after protracted stay-aways, and what exactly, if any, these difficulties are. It seeks to establish which skill listening-comprehension, writing, notetaking, speaking or reading - presents the most problems for these students.

The structured questionnaire was administered ten days after students had returned to lectures. The total sample consisted of 100 Practical English students who attended Language Laboratory sessions on one day. This sample is part of the total number of 355 students registered for the Practical English course.

There was a $100 \%$ questionnaire return and perhaps, because of the assurance of complete anonymity, all the questions with the exception of one question (7.6), were answered by the students. In the case of question 7.6 not every aspect of that particular question was replied to by students, and where there was no response it did not affect the outcome of the survey. The questionnaire and an analysis of it follow. The total percentages $(x)$ of the respondents to each question are given next to that question, as well as the number of those who did not respond, which is indicated by $(y)$.

\section{Questionnaire and analysis}

1 During the 2 months class

$\mathrm{x}=100$

disturbances did you read much in

$\mathrm{y}=0$ English?

$\begin{array}{ll}\text { YES } & 63 \% \\ \text { NO } & 37 \%\end{array}$

Just under two-thirds of the students felt they had "read much" while just over a third considered that they had not. The use of the word "much" is ambiguous but an analysis of those who answered in the affirmative reveals in 1.1 and 1.2 a clearer idea of what student perceptions of "much" reading involves.

1.1 If yes, what did you read? $\quad \begin{aligned} & \mathrm{x}=63 \\ & \mathrm{y}=37\end{aligned}$

(students were allowed to tick more than one)

$\begin{array}{lr}\text { Textbooks } & 17 \\ \text { Novels } & 37 \\ \text { Magazines } & 41 \\ \text { Newspapers } & 44 \\ \text { Other } & 3\end{array}$

Of the $63 \%$ of students who had felt they had done "much" reading (see Question 1 above) it is interesting that only $17 \%$ of the whole sample had read their university textbooks. Newspaper reading accounted for $44 \%$ of the reading done by these students and was by far the most popular form of reading material. This was closely followed by magazines $(41 \%)$ and then novels $(37 \%)$. The three students who had ticked "other" said they had read lecturers' handouts, law reports and comics. 


\subsection{Estimate of the amount of time $\mathrm{x}=63$ spent reading in English per day $\quad \mathrm{y}=37$}

Less than $1 / 2$ hour 8

1 hour 19

More than 1 hour 36

$36 \%$ of students read for more than one hour a day in English. However, in relation to the total number of students to whom this questionnaire was given just over a third of these students read for more than an hour a day in English - the other two-thirds did not.

\section{To whom did you speak in} English?

$$
\begin{aligned}
& x=100 \\
& y=0
\end{aligned}
$$

Fellow students

Members of your family 7

Shopkeepers

Others

No one

Significantly $97 \%$ of the students indicated they had spoken English to either fellow students, family members or shopkeepers. $20 \%$ under "other" had specified they had spoken English to a variety of people, for example, bursary sponsors, a priest, post office staff, telephone exchange staff, visitors, coloured friends, and in the case of one student - who is on study leave his colleagues at work. Only $3 \%$ said they had spoken no English at all during class disturbances.

\section{Estimate of the amount of time $\mathrm{x}=100$} spent listening to English on the radio $\mathrm{y}=0$

$\begin{array}{lr}\text { Less than } 1 / 2 \text { hour } & 27 \\ 1 \text { hour } & 16 \\ \text { More than } 1 \text { hour } & 35 \\ \text { Did not listen to English } & \\ \text { on the radio } & 22\end{array}$

$35 \%$ of the students spent more than 1 hour daily listening to English on the radio. The $22 \%$ who did not listen to any English and those $27 \%$ who listened for less than $1 / 2$ hour daily together represent $49 \%$ (almost $50 \%$ of the sample) whose daily exposure to spoken English on the radio was low.

\section{Estimate of the amount of time daily spent watching English

$$
\begin{aligned}
& x=100 \\
& y=0
\end{aligned}
$$
programmes on T.V.

Less than $1 / 2$ hour
1 hour 21

More than 1 hour $\quad 50$

Did not watch English programme on T.V. 16

During the student unrest, $50 \%$ of the students daily watched English programmes on T.V. In relation to those students who did not listen to English on the radio (22\%) television is a more popular medium for listening to English with only $16 \%$ not watching it.

5 Did you attend any functions that $\mathrm{x}=100$ were in English

$y=0$

YES 28

NO $\quad 72$

During the stay-away a significantly large percentage of students said they had not attended any functions where English had been spoken. $28 \%$ said they had been to functions where English had been the medium of communication.

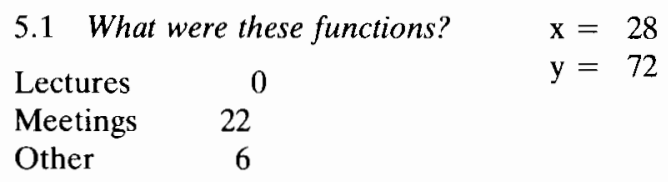

None of the $28 \%$ who attended functions in English went to any lectures, while $22 \%$ went to meetings conducted in English. Of the 6\% who attended other functions, $4 \%$ went to watch a dramatic play in English, 1\% attended church and $1 \%$ to a university graduation ceremony.

6 Did you do any writing in English? $\mathrm{x}=100$

YES $\quad 71$

$$
\mathrm{y}=0
$$

NO

Only a minority (29\%) had done no writing in English, while the majority $(71 \%)$ had written in English during the period of unrest.

\subsection{What did you write in English? $\mathrm{x}=71$$$
y=29
$$

Students who indicated they had done only one form of writing in English indicated as follows:

$\begin{array}{lr}\text { Lecture notes } & 7 \\ \text { Essays/Assignments } & 16 \\ \text { Letters } & 24 \\ \text { Other (please specify) } & 2\end{array}$

Some students indicated they had written combinations of lecture notes, essays and letters. 
These students are incorporated in the $71 \%$ who responded to the question.

Combination (lecture
notes,

$$
\text { essays, letters) } 22
$$

Letter writing was by far the most predominant form of writing as 19 of these students had combinations incorporating letter writing.

7 When you returned to lectures...

7.1 Did you experience any difficulties in understanding the sentences your lecturers were saying?

$$
\begin{aligned}
& x=100 \\
& y=0
\end{aligned}
$$

$\begin{array}{ll}\text { YES } & 23 \\ \text { NO } & 77\end{array}$

NO $\quad 77$

Over $75 \%$ of the students said they had no difficulties in understanding what lecturers were saying, while just $25 \%$ of students indicated that they had experienced difficulties in understanding sentences used by lecturers.

7.2 Did you experience any difficulties in following instructions $\quad \mathrm{y}=0$ given by your lecturers?

$\begin{array}{ll}\text { YES } & 22 \\ \text { NO } & 78\end{array}$

$22 \%$ said they had experienced difficulties in following instructions given by lecturers. $78 \%$ of the respondents had no problems in following instructions.

\subsection{Did you experience any} difficulties in extracting important $\quad \mathrm{y}=0$ points from the lectures you attended?

YES 37

NO

On the question of difficulties experienced in extracting important points from lectures, $37 \%$ of students experienced problems. $63 \%$ had no difficulty at all in extracting important points.

\subsection{Did you experience any $\mathrm{x}=100$} difficulties in taking lecture notes from $y=0$ the lectures you attended?

YES $\quad 36$

NO $\quad 64$

$36 \%$ said they had encountered problems with notetaking while $64 \%$ had no difficulties.
7.5 Were you required to speak in $x=100$ English without prior preparation? $\quad y=0$

YES $\quad 37$

NO 63

$37 \%$ of students were required to speak in English without prior preparation (e.g. in a tutorial) while $63 \%$ were not.

7.5.1 Difficulties experienced when $\mathrm{x}=37$ speaking English with... $\quad \mathrm{y}=63$

The $37 \%$ of students who said they were required to speak in English without preparation were asked if they had experienced difficulties with:

finding and choosing the right words

$\begin{array}{lr}\text { YES } & 30 \\ & 7\end{array}$

constructing sentences

YES $\quad 26$

NO 11

pronunciation of words

YES 21

NO $\quad 16$

The problem of finding and choosing the correct English words presented the most difficulties for $81 \%$ of the students required to speak in English, while pronunciation caused the least difficulty for only $56 \%$ of the students who had to speak in English without prior preparation.

7.6 Problems experienced in reading $\mathrm{x}=84$

printed English

$y=16$

$\begin{array}{ll}\text { YES } & 12 \\ \text { NO } & 72\end{array}$

graphs, tables

$\mathrm{x}=83$

YES $\quad 39$

$y=17$

NO 44

writing on blackboard $\quad \mathrm{x}=100$

YES $\quad 11$

$y=0$

NO $\quad 59$

overhead projector transparencies $\quad \mathbf{x}=90$

YES $\quad 35$

$y=10$

NO $\quad 55$

Of the various forms of written material difficul 
ties were mainly experienced in reading graphs, tables $(39 \%)$ and overhead projector transparencies $(34 \%)$. Printed English and blackboard writing presented fewer problems, $12 \%$ and $11 \%$ respectively.

\section{Students' comments $\quad \mathrm{x}=69$$$
y=31
$$

One way the questionnaire tried to monitor students' exposure to English during class disturbances as well as to monitor their difficulties with English was to elicit student reactions to the questionnaire. In this open-ended section $31 \%$ did not write anything. $14 \%$ of the students responded with writing "No comment", and are included in the $69 \%$ of students who are considered to have responded to the statement; "Any comments you may wish to add".

The remaining $55 \%$ of students who did react have been grouped, according to the comments they made, as follows:

- "The class disturbance did not affect me in coping with the work we are doing" -5 .

- "I like English very much the only problem I am now facing is the problem of getting more and more vocabulary. This is the thing that affects me the most in English e.g. finding and choosing the right words" -5 .

- "I seem to be improving since the two month's stay aways end" -2 .

- "I realise how much I have missed during class disturbances. I hope we would not get disturbed again" -6 .

- "English is less used during disturbances" 5.

- "Schoolwork is now congested and now I am appealing to the lecturers to reduce their pace and to offer limited work" -6 .

- "I would like to have some more basics in English so that I can understand it quiet [sic] easily" - 11 .

- "If I can practice [sic] to speak English then I can be alright" -9 .

- "I experienced much confusion on my return from class disturbances" -6 .

\section{Summary of the results}

In attempting to establish whether or not students' English suffers during disturbances at the University, we can summarise the findings as follows:

$-63 \%$ of the students felt they had "read much" during the disturbances.

- The major type of reading material read by students during this period was newspapers. Only a small minority (17\%) indicated they had read their university textbooks.

- Approximately one third of the students read for more than one hour per day.

- Almost half the students indicated that their conversations in English had been mostly with fellow students, while only a very small minority ( $3 \%$ ) had spoken no English at all.

- Listening to English radio programmes for more than one hour per day is favoured by one third of the students.

- Half of the students spent more than one hour a day watching English television programmes.

- A substantial number of students did not attend any functions conducted in English during the period of class disturbances.

- Of the small number of students who attended functions conducted in English, nearly all attended meetings.

- The majority of students had done some writing in English.

- Letter writing constituted the main format for writing in English by students.

- Three-quarters of the students had no problems on their return in understanding the sentences used by lecturers.

- The great majority of students experienced no difficulties in carrying out instructions given to them by lecturers.

- One third of students found it difficult to extract the important points from lectures.

- More than one third found notetaking a difficult exercise.

- Over one third of students were required to speak in English without preparation.

- Limited English vocabulary was the biggest obstacle for those students who had to speak in English without prior preparation.

- Most students had no difficulty in reading printed English or writing on the blackboard. About half the students experienced problems with reading graphs and tables. Just under $40 \%$ of students who responded said they had encountered difficulties in reading overhead projector transparencies.

- The majority of students' comments reveal that they are aware of the backlog of work that has to be covered; their need to practise 
speaking English; their lack of vocabulary in English; and their preference for easily understandable "simple" English.

\section{Discussion of the results}

It would seem from the student responses to the questionnaire that the vast majority of Practical English students were exposed to English during the period of unrest. But the level of that exposure can be questioned.

\section{Reading in English}

The picture that emerges is that approximately two-thirds of the students read much in English, although what constitutes reading "much" in English in terms of student perceptions is perhaps an unreliable indicator of how much they actually did read. This correlates with the findings of Proctor and Verschoor on the extent of contact with English claimed by black students. They found that "No definite conclusions can, of course, be made, because individual interpretations of the terms 'a lot of contact' and 'a little contact' vary from student to student" (1978:464).

In order to examine the students' own notions of what "much" reading in English is, the two questions on what they read and for how long were asked. Their prime source of reading material was newspapers and other ephemeral literature (e.g. magazines). Only a very few students $(17 \%)$ attempted to keep up with their course work by reading their textbooks. Proctor and Verschoor similarly found that "Newspapers seem to be more widely read than books" (1978:463). So it would appear that the standard of English contained in the reading material that the majority of students read was not of the same academic quality as is found in university textbooks. An interesting point to note here is that "students rarely receive books as presents", a fact which emerged in the survey by Proctor and Verschoor, who found that "In Group E no student admitted receiving a book as a gift, and in Group P only 4\%" (1978:463).

In terms of the amount of time spent in reading English daily during the two and a half months of student unrest, the majority spent less than one hour a day reading in English. This apportioning of their time to reading in English is obviously affected by conditions in the university residences as evinced by the following student comments:

"Most of the time it is difficult to concentrate on books during class disturbances because of the noise in the hostel e.g. radio and howlers."

"During the time of class disturbances I was not able to do all my normal activities."

"We do not read during these disturbances and even if we do it's usually not enough. Some do not at all."

\section{Speaking in English}

Students' interactions with mother tongue speakers of English during student unrest is extremely low, with $49 \%$ reporting that the conversations they held in English were with fellow students. While some students reported that the only time they were required to speak in English was to the telephone operators on the telephone exchange when they asked for a telephone number.

\section{Listening to English}

During this time student exposure to English as spoken on the radio is low, with only a minority listening to English radio programmes for more than one hour daily. The extent of peer group pressure may have some influence on this as one student writes:

"The problem is that at home they do not know English, they are not educated most of them. It is hard for me to listen to English on the radio because they will humiliate me."

However Proctor and Verschoor found "the general trend ... to be that students listen to radio and recorded music more at home than at university ... It might be, of course, that at home students have more time and opportunity to listen than at university" (1978:463).

The questionnaire did not ask to which radio station students tuned in to listen to English programmes. Therefore it is not possible to determine the quality of the spoken English that students heard. The quality of English in such terms as register, varies a great deal from one radio station to another. Nevertheless students need to be exposed to the English language in all 
its diversity which Wilkins (1974:35) says is "language that is rich in its structural range and realistic in its actualization. Such language might well not have been produced specifically for the language learner at all".

Half the students indicated that they watched English programmes on television daily for more than one hour. Again the questionnaire never sought to establish what programmes these were, but the fact that $84 \%$ of students watched English television programmes in varying amounts of time daily is significant. It would be interesting to have researched to what extent the visual material contributed to the students' understanding of the language content of such programmes.

While student unrest was in progress only a small minority of students attended functions that were in English. Not one student indicated that he or she had attended a lecture during this period. Although this is not surprising in view of the tremendous solidarity shown by students at such times not to attend lectures (arguably through intimidation by other students), it does reveal the fact that lecturers have little or no contact with their students during any protracted stayaway. As one student commented:

"Disturbances are of no profit to students. There is very little communication between students and lecturers if ever."

This inevitable breakdown in staff/student communication can create a variety of problems when students return to lectures. It can erode the trust and confidence in already established staff/student relationships to the detriment of all concerned. It can also cause problems for students when lecturers simply "pick up" where they had left off two months previously, assuming that students have kept up by reading textbooks, and have automatically remembered the work done previously in class. A student voices a complaint about this as follows:

"In poetry we didn't do the exercise which we have been given prior [to the class disturbances] with the lecturer and now I have difficulty in answering the questions on poetry because I don't know how to answer poetry questions."

And yet another student writes:

"During the two months disturbances, I found it difficult for me to read and understand some work as scheduled in the course outline without being briefed by a lecturer ... and as we returned to classes on Monday 19th May, it was difficult for me to connect the previously learnt material with the new information as some work, read during the disturbances, was wrongly interpreted."

Although if reading done during class disturbances leads to incorrect interpretation, this is far easier for lecturers to correct as students have the necessary background knowledge to what is being dealt with in class on their return. If, however, they have done no reading at all - how much greater is the amount of information that lecturers have to cover in class. This is compounded by "the lack of general knowledge among students [which] is even more serious, especially in subjects such as English, where general knowledge is an important prerequisite to the understanding of much of what they have to read" (Proctor \& Verschoor 1978:460).

Amongst the small minority of students who indicated they had attended functions in English, $78 \%$ of these students said that the function they had attended in English was a meeting. The fact that at student meetings the medium of communication is English is corroborated by a reference made by Kroes (1983:10) to an investigation conducted amongst Blacks throughout South Africa by G.K. Schuring of the Human Sciences Research Council in 1975, which revealed that "English is regarded by Blacks as a prestige language and a language for international communication. It is used at political meetings and at conferences".

And Meerkotter (1985:92) confirms this when he says of English that it "portrays the thoughts about political freedom of the minority of people in this country" and that "English has become the lingua franca and first language of South Africa". T.G. Reagan (1985) also says that English functions as a lingua franca in the multilingual black community in South Africa, and as the language of wider communication which provides access to the international community. Student comments would support this: "I would like to know more about English because it is spoken internationally."

"English is the only language we can use to communicate with other people. We stay with 
Zulu speekers [sic], Tswana speakers, etc. so we need it a lot".

Proctor and Verschoor say "It can be inferred from the answers to the questionnaire that most of these students are intensely aware of the importance of English as an international language and of the richness and status of English literature" (1978:465).

\section{Writing in English}

Most students (71\%) did some form of writing in English during the period under review, letter writing being the predominant. It is interesting to note that according to Schuring's work (as quoted in Kroes 1983:10) "letters are often written in English, even to relatives, in preference to the indigenous languages". LennoxShort (1970:2) maintains that for second language speakers "in personal letters it is permissible to write an approximation to conversational English for this informal communication, [is] often between people who know one another reasonably well ..." Lennox-Short also cautions that such ". . . conversational communication on paper is inevitably looser and (apart from dialogue) almost always weaker than what is accepted as an adequate written style". While students may well write essays and assignments during this period it seems they might well be prevented by the student caucus from submitting written work for evaluation by lecturers.

\section{Resumption of lectures}

It would seem that the majority of Practical English students who presented themselves for lectures after the period under discussion, were students whose exposure to English had been rather limited. Their coping skills too were severely tried when they returned to classes, to quote two students:

"I experienced much confusion on my return from class disturbances."

"It's difficult to cope up with a lot of academic work since there was a break in classes."

The demands made on most students to adjust from a period of relative inactivity and virtual seclusion from intellectual stimulation to the rigours of a full academic programme, where they are taught in English and bombarded with work, must be indeed frightening. One student referring specifically to the Practical English course writes that it: ". . . seems to be very wide, demanding and confusing. At least something must be done to minimise the amount of work bearing in mind that we have other courses to attend to".

Students are well aware of the volume of work they have missed and that they are expected to work at a faster pace. To quote some students' comments:

"I realise how much I have missed ... during class disturbances."

"If it was not for the class disturbances I could have gained a lot"

"I think these class disturbances really put me out of the way. I will just have to adjust myself to the present situation."

Proctor and Verschoor also found many of the student responses "implied that they are painfully aware of their inadequacies in the use and study of English" (1978:465).

Some students even suggest prolonging the academic year as a solution to overcoming the shortened number of teaching weeks left.

"We should not close during the June holidays so as to catch up all we have lost during the stayaway."

"My opinion is that we must not have the September vacation."

A few students profess also to being concerned about their lack of marks and the tests they have missed or still have to write.

"My only worry is that I have lost so many marks in my practicals and tutorials."

"I'm having problems on test dates. Sometimes you write three class tests on the same day. I think lecturers must meet before they decide on test dates or else they must ask students how they feel about writing a test on the date which would be proposed by the lecturer."

The necessary adjustment required of students to the lecturing situation that they are confronted with after student unrest is summed up by one student who writes:

"So far I have no problems may be because I am now familiar with the class disturbances as well 
as the pece [sic] which is often used after these class disturbances ie. crash courses."

\section{Lectures}

A substantial number of students said they had not experienced any difficulties in understanding the sentences their lecturers were saying when they returned to lectures. This is substantiated by some of the students' comments:

"I was very happy to find out that I'm still capable to understand what was said by the lecturers, i.e. I'm not that much lost after this 2 months period of disturbance. That have encouraged me to study hard and not to loose [sic] hope."

"English is never difficult to me as far as I am concerned."

"I can say that since I have engaged myself in reading, especially in English, I feel proud of myself because I didn't encounter any problems concerning notetaking in class as well [as] grasping and understanding what my lecturers was [sic] saying."

"It is not difficult to understand teacher's English provided it is simple English. Big words are boring, fortunately English teacher here at Fort Hare never utter a big word without explaining thereafter."

Wilkins (1974:34) cautions that “ . . if the learner's exposure to language is only exposure to carefully-controlled language, it is only this kind of language that he will learn to comprehend."

Amongst those students (who constituted the minority) that experienced difficulties when they returned to lectures in understanding what lecturers were saying was one student who remarked:

"I would like that the lecturers speak as high as they can and pronounce their words clearly. We take a long time to write notes because we struggle in trying to imagine what the person might be trying to say."

\section{Lecturers' instructions}

Again regarding the question about following instructions given by lecturers, a considerable number of students $(70 \%)$ experienced no problems.
"I can say I do really understand when a lecturer has given me instructions on what to do. By making use of readings, speaking, writing English I find English it is a little bit easier to understand it."

Conversely another student who did experience problems wrote:

"I am not yet properly understand instruction. But is also confusing."

\section{Extracting important points}

When it came to the problem of extracting important points from lectures, the number of students who had no difficulties dropped to $63 \%$.

The significant increase in the number of students who had trouble with extracting important points highlights a problem area and is endorsed by one student who wrote:

"At the present moment English is being understood although there some problem in a certain part of work - extracting important points."

\section{Notetaking}

The rise in the percentage of students encountering problems in extracting points from lectures remains almost constant, similarly the number of students who had difficulties with taking notes. This problem could be attributed to the pace at which lecturers spoke, as attested to by some student comments:

"The problem I experienced was not due to language, but due to the pace at which lecturers were lecturing."

"The lecturers are so fast, and they are piling us with a lot of work in such a way that I cannot do the whole work given because of the lack of time."

"The 2 months disturbances causes frustration to me because there is too much work to cover. Lecturers are rushing so that by the end of the year they will be through with their work and left us blank."

\section{Speaking in Lectures}

Just over one third of the students were required to speak English without prior preparation. The need for English fluency is important for students who commented: 
"I need to speak English daily and every time so as to enable me to be fluent."

"We Science students do encounter problems when coming to English speaking since most things we do are figures and no assignments."

"With English language I am good in listening and reading. The problem lies with the output, meaning that I am not that fluent in speaking and when I write a letter, it takes me quite some time trying to arrange and select words or phrases that will convey the exact impression."

The vast majority of the students who had to speak in English without prior preparation did experience problems in articulation, especially with respect to finding and choosing the right English words, constructing sentences in English and with the pronunciation of English words. Students commented on these trouble areas.

"The problem I find most disturbing is choosing the right words condusive [sic] to the context."

"I usually find problems in constructing sentences and in pronunciation."

"Even though I occupied my time during the disturbances by reading and listening, [to] as much English as I can, I still had a problem of phrasing my opinions in English, especially in speech."

The masteries of the pronunciation system always pose problems for second language learners, as Wilkins (1974:31) affirms: "Many adults who otherwise acquire an excellent command of language never overcome the difficulties posed by a new sound system". And according to Mawasha (1978:2) "oral English including pronunciation and intonation, has always presented difficulties to both the Black ESL teacher and his pupil".

Overcoming personal shyness and inhibitions also presents considerable difficulties for students.

"If the lecturer ask [sic] the question I'm afraid of answering a question or to comments [sic] about [a] question because of my poor English."

"In talks I usually [am] overcome by fearness which make $[s i c]$ me to be shy although I know a thing."

It is obvious that these students require more oral practice in speaking the language, and several support this idea. One student writes:

"I think that there are to be more practices made so that I can speak English properly and find no problems or difficulties while listening to English programmes especially in radios and $I$ also have difficulties in some other novels that I come across or I happen to read."

\section{Reading English in lectures}

The reaction of most students to reading printed English material was mostly positive, only a small percentage $(12 \%)$ having difficulties. However, reading graphs and tables was more problematical for students, and those who experienced difficulties as opposed to those who had no difficulties can be reflected as a ratio of 39:44. The majority of students confirmed that reading writing on the blackboard did not pose a problem. But a large number of students made heavy weather of reading overhead projector transparencies. This is substantiated by a student who said:

"It is difficult for one to read what is written on the overhead projector transparencies if the notes are not clearly printed and written."

\section{Students' attitudes to English}

It is clear from many comments that students derive much pleasure from the English language and they look forward to further encounters with the written word. Referring to reading English in general, two students wrote:

"I love English so much. Most of the time I read novels. I have so many novels. I am very much interested in English."

"I am enjoying reading, speaking English all the times."

Proctor and Verschoor corroborate this when they report that "a favourable attitude towards a subject is one of the pre-requisites towards success in that subject. It was therefore illuminating to find a stated preference for English rather than Xhosa both as a teaching medium and as a subject, both at school and at university" (1978:464).

The desire to improve their English proficiency is manifested by students who stated that they: 
"Wish to upgrade my English before the end of the year."

"As I am attending lectures no [sic] I hope I will improve my English as much as I can."

"It is my sincere wish to know English as I know myself but due to time limiting factors I can't afford. Had there been no school disturbance this year, I would try to read as many literatures as possible to aquaint [sic] myself with."

This would support Wilkins' (1974:3) contention that "the ultimate aim in learning a second language must generally be to achieve the same flexibility, the same linguistic creativity, that the native speaker possesses".

An awareness of the obstacles English creates and of the need to master the language is borne out by the comments of some Practical English Students:

"I'm still not knowing the direction of English and how would you present it for exams."

"I can say that it is of more importance for someone to involve himself or herself in reading newspapers, novels, etc. so that he/she might not encounter any problems coming to [the] language. This might also help him in increasing his vocabulary so as to move or go smoothly in communicating with his lecturers and as well as notetaking in class."

\section{Use of the language laboratory}

The need to avail themselves of the facilities of the Language Laboratory in order to help improve their English is also commented on by students.

"The Language Laboratory helps me a lot."

"The programmes are very important and useful. I realise how much I have missed."

“.. .my interest in the Language Laboratory course is beyond control."

"Many of the exercises being done in the Language Laboratory are very much helpful especially to those [whose] English is the third or second languages."

\section{Literature survey and recommendations}

This section will try to put the results of the questionnaire into perspective and attempt to correlate them with research done by others in the field of second language teaching of English, with a view to providing a blueprint for action after future class disturbances.

We first need to examine the milieu that these Practical English students have come from prior to their entering the University of Fort Hare. For despite the fact that these black students at the University have completed at least ten years of English at school, passed all their matriculation subjects through the medium of English and have been exposed to English radio and television in varying degrees, one would hardly perceive such students as having an inadequate knowledge of English. On the basis of their experience at school, a lecturer should be able to assume that these students have a high level of linguistic competence. Furthermore, these students whose mother tongue could be either Sotho, Tswana, Zulu, Xhosa, or even Afrikaans, can be regarded as "highly sophisticated linguistically as they could switch from one code to another ..." (Rogers 1976:27).

The findings of this survey suggest that students are hampered by a limited vocabulary and largely confined to their university residences because of peer group pressure to keep away from lecture halls, the university library and lectures' offices. Their contact with English speakers is severely curtailed. One can assume that the English of the majority does indeed suffer during this period, especially as Wilkins (1982:33) has reflected ". . . what people learn is determined by or reflected in the nature of the activities they engage in. One aspect of the child's exposure to language is that he spends much more time hearing or listening to language than he does in producing it. This is directly reflected in the type of language ability that he develops". Dulay, Burt and Krashen (1982:14) have pointed out that it is also the quality of the language environment that is of paramount importance to success in learning a language. It is Wilkins' belief that this ". . . language learning should take place in a rich linguistic and cultural environment . .." (1982:39-40). This would lend credence to Burton's view that "Proficiency in using language - in listening and speaking; in reading and in writing - is basic to learning and living. The provision of opportunities for students to practise these skills is now generally recognised as a necessary element in their 
studies. Without such opportunities, progress in specialist fields is impeded; and ability to use academic and vocational attainments in work and to relate them to social and personal life is diminished" (1976:vii).

The low level of student exposure to English during student unrest is compounded by the fact that the present system of schooling has resulted in students entering the University with an extremely poor command of English. Indeed, the findings of Proctor and Verschoor "confirmed the suspicion that Black students reach university and register for courses in English with very little reading or literary experience behind them" (1978:462). W. Maneli, in a paper delivered at an Alice Teachers' Union Seminar, also confirms this when she says that "aspiring to higher learning (University) is still the GOAL of the average Black pupil - learning English for communication has not caught on" (1985:4). The fact that even if these pupils realise when they enter University that they will need to listen to lectures in English, make notes in English and write examinations in English means that this "realisation of the importance of linguistic competence does not, however, solve the inherent practical problems. The demands of specialist studies leave too few 'contact hours' available for the practice and discussion of 'everyday English' - a limitation that presses as hard upon those whose field is literature as upon those who are economists, geographers, scientists, sociologists or historians" (Burton 1976:vii). And yet Proctor and Verschoor found "that students have twice as much contact with 'a lot' of English at University (apart from lectures in English courses) as they have at home". This they say "is understandable, since English is the medium of instruction" (1978:464).

Although English is the medium through which school subjects are 'taught' to black school pupils, "every teacher is virtually a teacher of English because he presents History/Social Studies/Science/Maths./etc. in English" (Maneli 1985:2). This view is supported by Penny who says "every teacher who teaches through the medium of English is a teacher of English" (Grocott's Mail, 1 August 1986). So each teacher is faced "by a mammoth task - that of having to teach it as a foreign/second language to nonspeakers of the language and to fight his limitations 'somehow', being a non-speaker himself"
(Maneli 1985:3). Penny also agrees that "one finds teachers who are ill-prepared, unsure of their own grasp of English, and too insecure to use English in the classroom with anything like the fluent competence which would help to break the negative cycle of inadequate English language use and poor academic performance" (Grocott's Mail, 1 August 1986). And yet this was achieved up until thirty years ago "with laudable success" (Maneli 1985:3).

Maneli underlines the seriousness of the problems facing Black education: "Since we are fully aware of the fact that our children hear English and dabble with it for a few hours a month only in class, CANNOT WRITE IT CORRECTLY at all levels as part of schoolwork; cannot hope to earn their bread and butter with it in this country or abroad; use Xhosa or another ethnic language at home and among themselves, during class lessons with the teachers; listen to Xhosa over the radio and TV2; the majority do shopping in Xhosa in townships and homelands - are we surprised at the alarming rate of failure ..." (1985:4).

Maneli also exposes the dire problem which teachers face in black schools; the fact that the masses of disheartened pupils are convinced of the futility of all learning at school. School pupils are rebellious of the present education system and do not see a future for themselves in a technologically advanced age. These pupils, "thousands of them, have become so bored with exasperating criss-crosses of the red ballpoint pen . . . the destructive letter $F$ after 10 months in the drab classroom . . . the painful ordeal of sitting in the desk (literally sitting) for over four hours [sic] each day LISTENING . . .the backbreaking task of having to 'read' textbooks 'on your own' to be able to do homework ... . when what is read cannot be comprehended" (Maneli 1985:4). It is little wonder that the future is so bleak for these pupils and the helpless plight of the teachers at these schools is evident when Maneli poses the question - "If they do not pass with comprehension, master vital subjects like Science, Maths, Biology, owing to their poor READING ability (assuming we agree that ORAL interaction in class in English is grossly lacking, and therefore pupils cannot be inspired to read 'on their own' with understanding; and the basis of success in content subjects is READING AND WRITING WITH UNDER- 
STANDING), how will they fit in the world of computers/Marine Biology/Transplant Surgery/ Nuclear Testing, to name a few?" (1985:5). The level of achievement of school pupils is deteriorating every year so that what Maneli says of them is equally applicable to the black students entering the University - ". . . in 1985, we admit that English has deteriorated in all respects to such an extent as to cause despair" (1985:2).

In order to correct this course of events the answer would appear to lie in promoting student motivation. Learning English requires considerable motivation on the part of the student. H.D. Brown asks "how can a language teacher provide extrinsic motivation where intrinsic motivation is lacking?" Research by Gardner and Lambert (1972) and Spolsky (1969) reveals that when a student wanted to integrate himself with the culture of a second language group, to identify with and become part of that society this integrative motivation achieved greater success in successful language learning. This is substantiated by work done by Wilkins (1982:38) which has disclosed that "learners who are interested in the language and culture for its own sake and who are potentially sympathetic to the values of a different society [are] . . . the more successful language learners" as opposed to those "who are learning a language for some specific purpose, perhaps because it is going to be useful to them in some way". It would appear from Meerkotter's (1985:92) research that "English has risen as a trans-cultural force in South Africa", therefore the language and culture must be promoted if we are to eradicate the present deadlock at schools and universities. It is indeed Maneli's (1985:8) contention that "We need to adapt our whole outlook to the place of English in our lives as Black people and only then shall we be inspired ..." Meerkotter (1985:93) believes that "South Africa is moving towards monolingualism in the sense of having a particular language as first language. This could also allow for a situation in which certain regional languages emerge as 'second' official languages". Perhaps if this trend accelerates spoken English will really become the lingua franca of South Africa. It is the contention of Maneli that "We need to restore English as the spoken language at school ..." (1985:8).

It seems then that a greater desire to rectify the previous limitations of the schooling system and to try to communicate through English all the time would create stronger motivation and would ensure effective learning. This would correlate with Van der Walt's view that language "must be seen as interpersonal communication, used for a whole range of purposes and in a wide variety of situations" (1984:21). In the case of weaklymotivated students the benefits of language learning must be kept to the fore and Wilkins advocates "a strong element of play, humour and entertainment" (1982:54). Additionally if students lack motivation this can in some instances be attributed to their attitudes. Students who have rigid, ethnocentric and authoritarian views are "less successful in language learning" according to Wilkins (1982:53). Wilkins also asserts that "the attitudes of children are almost always the attitudes of their parents also, so . . . parents do much to determine the lack of success of their children in learning a foreign language". This problem can perhaps be averted if languages are taught 'in a rich cultural context'.

It is possible to infer from the data available that many students believe they understand enough English to 'get by'. Wilkins (1982:38) writing about language acquisition says that students ". . . tend to learn a second language to the level that is necessary for them to meet whatever communication needs they can themselves identify". But as Kroes (1984:8) concludes: "'Knowing' a language (competence?) involves more than the ability to recognise or to compose correct utterances: it includes the ability to use such utterances appropriately in acts of communication, within the context of longer discourse. In other words: communicative competence". It is also Van der Walt's conviction that while "a student may know the grammar and vocabulary of a language and yet still be unable to begin and end a telephone conversation appropriately, or be unable to excuse himself from other people's company, or he may not know how to make sure his listeners understand that he is uncertain about something" (1984:21). The key concept in such communicative activities is thus 'getting the message across'. It is therefore essential that these Practical English students realise "the trend in linguistic description is towards communicative functionalism" (Kroes 1984:8).

The recent changes to the syllabus at black schools from the formal grammar and "the oldfashioned approaches' of 50 years ago" (Maneli 
1985:4) to a communicative approach has required a significant re-adjustment on the part of teachers. Rita Ribbens (1984:45) refers to this change in the syllabus: "In the traditional approach the teacher becomes more of a manager, or director who has to stimulate interaction and therefore develop materials to suit the needs of his pupils". Traditional language teaching syllabuses were structurally organised (Van der Walt 1984:20) but this often resulted in what Newman (1979) calls the 'structurally competent" student. This would be the student "who knows his grammar, but who is unable to perform a simple communicative task and who cannot communicate with a native speaker of the language" (Van der Walt 1984:20). This is corroborated by Johnson (1982) who speaks of the phenomenon of the "structurally competent but communicatively incompetent student".

The amount of time Practical English students spent reading in English per day during student unrest highlights the fact that students on the whole have highly unrealistic time commitments to actual language study. Wilkins (1982:31-2) claims that "one year in the classroom provides the equivalent of from one to three weeks' contact in a language-acquisition situation. If it takes from three to four years for a child to learn his mother-tongue to a reasonable degree of proficiency, we can work out for ourselves the astronomical length of time it would take for language learning to reach the same level if it was based on the same kind of largely random exposure to language". It is Wilkins' firm belief that "it is very rare for an individual to develop as comprehensive a knowledge of a foreign language as the native speaker" (1982:25). And yet ". . adequate comprehension is the doorway to good judgement ..." (Lennox-Short 1970:135).

The time factor in learning a language or any other subject through the medium of English affects lecturing staff as well. Proctor and Verschoor's tentative conclusions were that "on the whole, it would seem that many of these students suffer from an impoverished background in and experience of English language and literature. The extensive reading and study of English, as well as the love of the language and literature that prospective students of English might reasonably be expected to have cultivated before they arrive at university has not been the lot of the majority of Black students. Consequently a great deal of lost time has to be made up at university, and the task of the lecturer is made correspondingly more difficult, in spite of the generally favourable attitude towards the subject on the part of the student" (1978:465). If the academic year has been disrupted by class disturbances, lecturers find themselves in a situation where they have to cover the syllabus but have an inadequate fixed amount of time in which to reach their objectives. In preparing students for end-of-year examinations, the lecturer has unrealistic requirements imposed upon both him and the student and can "only effect some kind of compromise between what he is expected to achieve, what he would like to achieve and what conditions permit him to achieve" (Wilkins 1974:44).

The lecturer has a key role to play in developing student confidence, which in turn will encourage perseverance with the communicative approach to English by students. To be avoided at all costs is ". . . hostility towards the teacher" and lecturers should have the skill and personality to create "the conditions for learning" (Wilkins 1982:53). Considerable methodological innovation will also be meaningless if the lecturer does not have the ability to "put it across": modern communicative methods "require more careful preparation and a greater display of pedagogic skills than more conventional methods" (Wilkins 1982:55). Lecturers also need to be sensitive to student attitudes and "adopt an intuitive flexibility that so often distinguishes the good teacher" (ibid).

Although McLarty's research was not addressed to teachers at tertiary level, what he says about secondary teachers is largely applicable to lecturing staff engaged in teaching predominantly black university students. McLarty (1985:39-40) stresses that all teachers (including content subject teachers) should emphasise the importance of reading and realise that good listening and good reading go together. The process of learning whereby students become less and less dependent on the lecturer cannot take place without students having developed reading skills. Proctor and Verschoor's 'suspicion', "that students ... have done very little reading of English apart from the few books prescribed for Junior and Senior Certificate ..." (1978:460), was confirmed when they found that "more than 
half of the two groups tested had read fewer than 10 works of fiction in four years prior to leaving school . . ." (1978:462). This supports McLarty's contention that all teachers should "devil's advocate' the use of textbooks" for reading as opposed to "the reading of extra sources such as newspapers" (1985:40). And Ribben (1984:55) agrees that "set work can be made communicative by the unimaginative teacher, though all genres do not lend themselves equally well to this". Based on the premise that every teacher is a reading tèacher, McLarty (1985:40) suggests that "skills are effectively taught by 'reciprocal' teaching . . . because where content material is genuinely difficult, as it may be in poems, complex explanations of physics, and uncomfortable history (that is, contrary to the commonly accepted version), the high school child needs to be assisted to read it himself'. This is vitally important for poor readers of English as they "often do not notice when a section of text makes no sense, and do not look back for help to try and find where they lost the trail. It is almost as though they do not expect it to make sense anyway (McLarty 1985:42). Amongst such weak readers of content material there is often "a return to anxious word by word decoding instead of breaking free to guess and test" (McLarty 1985:43).

If lecturers need to promote the communicative approach by adequate exposure to English through the reading of textbooks, their task is also to encourage fluent oral expression. Of course, as Babst (1984:20) says, "where fluency is the primary objective, students can be expected to make more errors in the second language". This is consistent with Adendorff, Chick and Seneque's findings that student concern is for "increasing fluency in . . . use of English rather than a concern with learning formal grammar and improving pronunciation" (1985:73), and this they argue requires a "move away from a 'deficit' view of these learners, necessitating the teaching of formal grammar . . . to a programme concerned with developing confidence and encouraging risk-taking behaviour ..." (1985:73). It is essential that lecturers reassure students that making mistakes is an inevitable and a necessary part of learning a language. As Babst (1984:20) explains: "Unlike the exponents of behaviouristically based approaches who try to avoid incorrect responses at all costs, audio-linguists take a more forgiving view of errors" and that "error correction is a useful tool, but it should never be overemphasised". Van der Walt (1984:26) believes that "fluency work involves free communication. The student is evaluated at the communicative task level; he is assessed whether he can communicate successfully, whether he can produce and respond to a message, even though he makes mistakes. During this activity the teacher should refrain from making linguistic corrections". It is evident from the Practical English students' comments that they greatly fear the risk of exposing themselves as communicatively incompetent in the presence of their lecturer and fellow students. It is important to remember that "no language skill is so difficult to assess with precision as speaking ability" (Harris 1969:81). If students are encouraged to develop their spoken English this has a spin-off in that it could also improve their written English because spoken English "is more easily transferred to the written medium than the converse" (Wilkins 1982:62). The difficulties students experience in speaking the language are typical according to Wilkins of "learners taught by largely traditional writingbased methods" (ibid).

Lectures need also to bear in mind "contextualization cues": verbal and non-verbal behaviour signalled by their students. They need to be aware of the politeness strategies identified by Scollon and Scollon (1982), where, on the one hand a student may be voluble (which would suggest a willingness to negotiate his world view with others) and on the other hand a student may be taciturn (which would suggest deference politeness and a disinclination to negotiate his world view with others). This connection between "solidarity and deference politeness strategies with volubility and taciturnity" (Adendorff, Chick \& Seneque 1985:48) is intimately connected with the level of risk-taking by successful language learners. "In other words, successful learners are those who are prepared to take the risk of being wrong publicly, with its attendant risk of face loss. Since those who are voluble expose themselves to this danger more than those who are taciturn, it would appear that there are advantages in encouraging solidarity styles of interaction in situations where language learning is to be encouraged" (ibid). This strategy would be particularly useful in tutorials where lecturers often have great difficulty with 
student passivity in eliciting any response to questions.

Extensive use of self-access materials and media such as provided by the Language Laboratory and CAI (Computer Assisted Instruction) are essential to assist students.

These materials enable students to devote time to catching up on work missed during boycotts and to filling in gaps in their general knowledge. This is suggested in an attempt to remedy what Proctor and Verschoor describe as "two of the basic and at times daunting difficulties encountered in giving instruction and delivering lectures . . . are the serious lack of the African student's 'background' knowledge of a literary, historical and social nature, and his general ignorance about even minor aspects of cultures, religious and social mores other than his own" (1979:459).

\section{Conclusion}

Throughout this paper the underlying assumption has been that students' lack of exposure to English during periods of unrest hampers their progress when they return to lectures.

It is my contention that if student disturbances are only of a few days' duration, or, if they occur intermittently (spread over a few weeks) their effect is not so devastating on the year's academic programme because the momentum of lecturing is maintained. Academic performance is not disrupted significantly when there is regular staff/student contact. However, when disturbances are protracted and students are away from lectures for a considerable number of days in succession, communication between staff and students is definitely affected and students' proficiency in English is appreciably lowered.

Furthermore, lecturer support for students to try and overcome the difficulties caused by being taught through the medium of English is vital. In addition to taking into account the generally limited exposure students have to English during stayaways, lecturers' attitudes are crucial at such times in helping students re-adjust to a full lecturing programme. There is a distinct need to settle students' unease and in a nurturing way to get them back into the academic swing of things. This ability to bolster student confidence and to help students bridge the transition during the critical readjustment period until lecture atten- dance has stabilised and returned to normal pays dividends for lecturers. It hastens the re-establishment of staff/student communication. Likewise I contend that it aids in positive feedback from students. In order to support this viewpoint I quote from a students' comment: “. . I I appreciate the lecturer's to be nice and considerate with us, more especially in my Practical English (as a whole). I thank you for being so helpful and encourageous". [i.e. encouraging]

There may well be other effects of student unrest outside the scope of this paper which could be researched.

\section{Bibliography}

ADENDORFF, R., CHICK, K. \& SENEQUE, M. 1985. Negotiating meaning in an English cultural environment a course for Afrikaans bankers. Journal for language teaching 19(2).

BABST, C. 1984. The monitor as manager of learning. Journal for language teaching 18(3).

BROWN, H.D. 1980. Principles of language learning and teaching. Englewood Cliffs: Prentice-Hall.

BURTON, S.H. 1976. Using English: a language course for advanced students. London: Longman.

DULAY, H., BURT, M. \& KRASHEN, S. 1982. Language two. New York: O.U.P.

EVANS, T. 1982. Teaching English. London: Croom Helm.

HARRIS, D.P. 1969. Testing English as a second language. New York: McGraw-Hill.

JOHNSON, K. \& MORROW, K. ed. 1982. Communication in the classroom. London: Longman.

KROES, H. 1983. Upgrading second language skills: manpower development in a developing country. Journal for language teaching 17(1).

KROES, H. 1984. The notional-functional approach to curriculum design and lesson planning. Journal for language teaching 18(2).

LENNOX-SHORT, A. 1970. Effective expression. London: Evans Bros. Ltd. 
McLARTY, A.H. 1985. Secondary reading and the future. Journal for language teaching 19(1).

MANELI, W. 1985. English in Black schools through the 80's to 2000? Paper presented at Alice Teachers' Union Seminar held at Phandulwazi Agricultural High School, 7 December 1985.

MAWASHA, A.L. 1978. The potential value/effectiveness of the Language Laboratory in language teaching with special reference to pronunciation and intonation in ESL in Black education, S.A.A.L.T. Newsletter 12(2).

MEERKOTTER, D.A. 1985. Moving towards monolingualism in a multicultural society: an educational perspective. Journal for language teaching 19(3).

NEWMARK, L. 1979. How not to interfere with language learning, in BRUMFIT, C.J. \& JOHN$\mathrm{SON}, \mathrm{K}$. ed. The communicative approach to Language Teaching. Oxford: O.U.P.

PRACTICAL English: a guide to the Practical English Course. 1986. Alice: University of Fort Hare.
PROCTOR, L. \& VERSCHOOR, E.N.E. 1978. Black students and the study of English. Fort Hare Papers 6(6).

RIBBENS, R. 1984. Methodological implications of the functional-notional approach. Journal for language teaching 18(2).

ROGERS, E.M. 1976. Communication in Organizations. New York: The Free Press.

SCOLLEN, R. \& SCOLLEN, S. 1982. Narrative, literacy and face in intercultural communication. Norwood [N.J.]: Ablex.

VAN DER WALT, J.L. 1984. The functionalnotional approach: an introduction. Journal for language teaching 18(2).

VORSTER, J. \& PROCTOR, L. 1976. Black attitudes to "white" languages in South Africa: a pilot study. The Journal for psychology 92.

WILKINS, D.A. 1982. Second-language learning and teaching. London: Edward Arnold. 